\title{
Crimen perfecto. El manual de la impunidad en México
}

\begin{abstract}
A nivel mundial México ostenta los mayores índices de impunidad y desaparición forzada. Generalmente los crímenes no son castigados o ni siquiera son investigados. Por desconfianza la ciudadanía no suele reportar los hechos delictivos ante el temor de que las autoridades estén coludidas con los criminales. Los procesos políticos que asentaron el régimen autoritario posrevolucionario y la posterior transición fallida

a la democracia son determinantes de los altos grados de violencia e impunidad que se verifican en México durante las dos últimas décadas. No es un fenómeno de violencia social o de bandas criminales autónomas, sino que responde a la descomposición del sistema político, que no ha sido reemplazado por un modelo democrático en el que se garantice la legalidad y el castigo a la delincuencia.
\end{abstract}

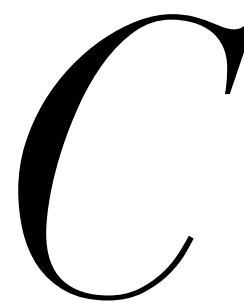

ON DATOS muy recientes, investigadores de la Universidad de las Américas Puebla (UDLAP) destacaron que México, medido con 59 países, ocupa el penúltimo lugar entre las naciones con los más elevados índices de impunidad. Al presentar el estudio Elíndice de impunidad global, que analiza información de ig3 Estados miembros de la Organización de las Naciones Unidas (ONU) que generan información estadística, Juan Antonio Le Clercq, coordinador del Centro de Estudios sobre Impunidad, indicó que "sólo 5y naciones fueron motivo del estudio por contar con información estadística

* Docente-investigador de la Unidad Académica de Estudios del Desarrollo de la Universidad Autónoma de Zacatecas, México. suficiente y actualizada en materia de seguridad, justicia y derechos humanos". Por su parte, Andrea Ambrogi Domínguez, presidente del Consejo Ciudadano de Seguridad y Justicia de Puebla, quien también participó en la investigación, presentó los resultados para México en materia de impunidad y resaltó que México tiene cuatro jueces por cada roo mil habitantes, cuando el promedio internacional es de i7. "Estamos lejos de un escenario ideal”, expresó. Los países con menor impunidad tienen 45 jueces por cada roo mil habitantes. Hizo notar que en el caso de las desapariciones forzadas, "México tiene una calificación de cero, por el alarmante número de desapariciones forzadas de personas".'

Para 2013, en 93.8 por ciento de los crímenes cometidos en el país, los culpables no fueron castigados 


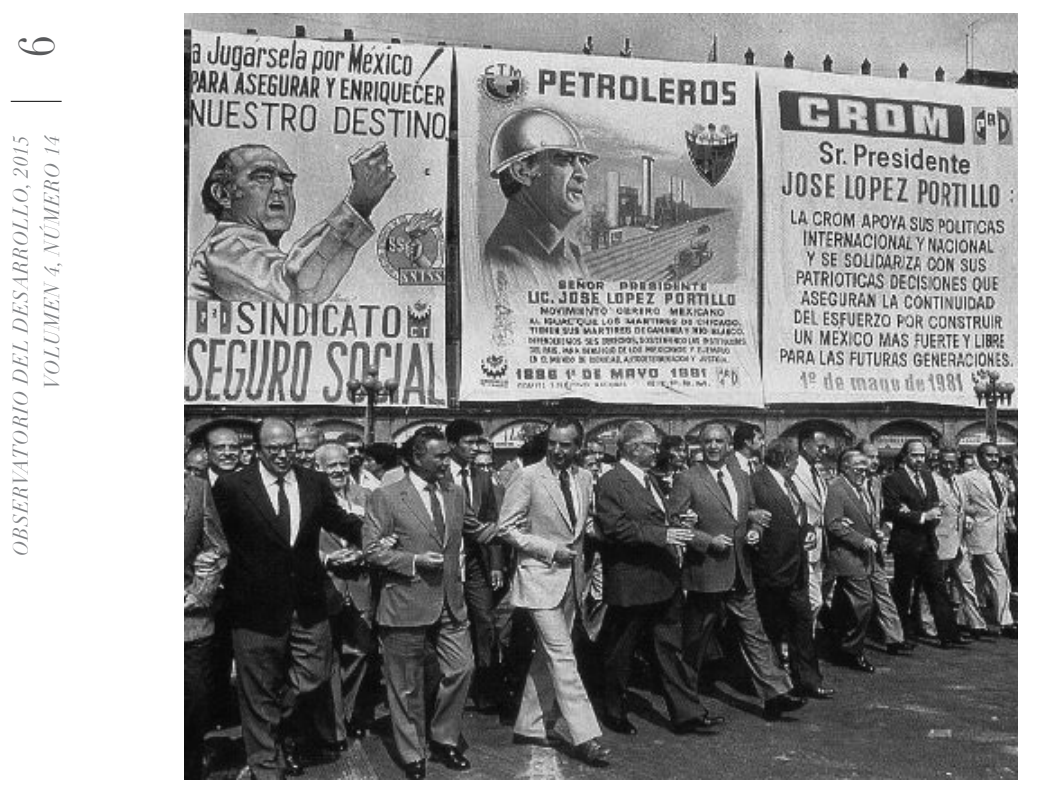

Por más de siete décadas el partido de Estado controló a las grandes organizaciones obreras, campesinas y populares.

o ni siquiera se realizaron investigaciones. Otros casos no fueron reportados por temor a la conducta de las autoridades y desconfianza de que en muchos crímenes las propias autoridades estuvieran coludidas con las bandas y ejecutores de tales actos. Según una encuesta realizada por Americas Barometer, México figura entre los países que tienen el nivel más alto en toda la región en relación con la percepción de impunidad y desconfianza en la aplicación de la ley por las autoridades.

Violencia e impunidad casi son parte del mismo proceso. En sociedades donde no se castiga a los delincuentes, sean del tipo que fueren, la comisión de delitos, conductas ilegales y todo tipo de violaciones prosperan como hongos en suelo húmedo. Hice mi carrera de abogado en la Universidad Nacional Autónoma de México (UNAM) y nunca olvidaré que en la clase de Derecho penal el profesor Fernando Castellanos Tena lanzó la sentencia de que "delito que no se castiga, se repite". Y eso es lo que ha pasado en México desde hace muchos años. La diferencia es que bajo la hegemonía del partido único, entre 1946 y I982, con un sistema altamente autoritario, el Estado tenía el control político y social a escala nacional, y toda conducta delictiva, sea cual fuere su naturaleza, era vista como contraria al dominio férreo de ese sistema. Las represiones políticas, asesinatos, corrupción y otras conductas delictivas no fueron castigadas y en muchos casos ni siquiera se realizaron investigaciones por parte del Estado, ya que en la mayoría de los casos éste era su agente principal. La hegemonía política absoluta se imponía como fundamento para cualquier acto ilegal proveniente del propio Estado.

Los medios de información estaban controlados por el Estado y el espacio de la comunicación frecuentemente omitía, distorsionaba, confundía o mentía sobre los hechos, motivo de estos actos delictivos en los que había participación directa del Estado o funcionarios a su servicio. Esto ha sido y sigue siendo, con honrosas excepciones de comunicadores valientes e independientes, una de las reglas básicas del manual de la impunidad en nuestro país.

Los sistemas autoritarios - y el mexicano de aquellos años lo era en grado superlativo - colocan a los agentes y funcionarios del gobierno con una amplia libertad (impunidad) para ejecutar cualquier tipo de conducta, la que se presenta como razón de Estado. El régimen político mexicano había emanado de la Revolución de I9IO-I9I7 y este origen servía de fundamento principal de su legitimidad. Por lo tanto, asumimos que en el caso de México han sido los procesos políticos que desembocaron en el régimen autoritario posrevolucionario, posterior a I940, así como la fallida transición a la democracia en la que el país se ha visto envuelto desde 1997 (en la que el Partido Revolucionario Institucional [PRI] perdió el control del Congreso), los que han determinado los altos grados de violencia e impunidad en México en las dos últimas décadas. No se trata de un fenómeno de violencia social ni de bandas criminales autónomas que salieron de la nada, sino de la evolución y consecuencia de la descomposición de todo un sistema, sin su reemplazo democrático en el que la legalidad y el castigo a delincuentes de todo tipo sea el elemento central del régimen.

\section{Corporativismo, Clave del monopolio de la VIOLENCIA dEL Estado MEXicano}

Como vamos a explicar enseguida, el corporativismo del sistema de partido hegemónico implicaba el control de grandes corporaciones obreras, agrarias y el llamado sector popular. Desde la gestión cardenista y en especial desde la transformación del Partido Nacional Revolucionario (PNR) a Partido de la Revolución Mexicana (PRM) en I938 y, posteriormente, en el PRI en I946, el dominio político en México se estructuró a partir de la integración de grandes sindicatos obreros y campesinos. Durante estos años se fue construyendo una gran pirámide política y social en la que la dirigencia en la cúspide tenía el control de todas las zonas 


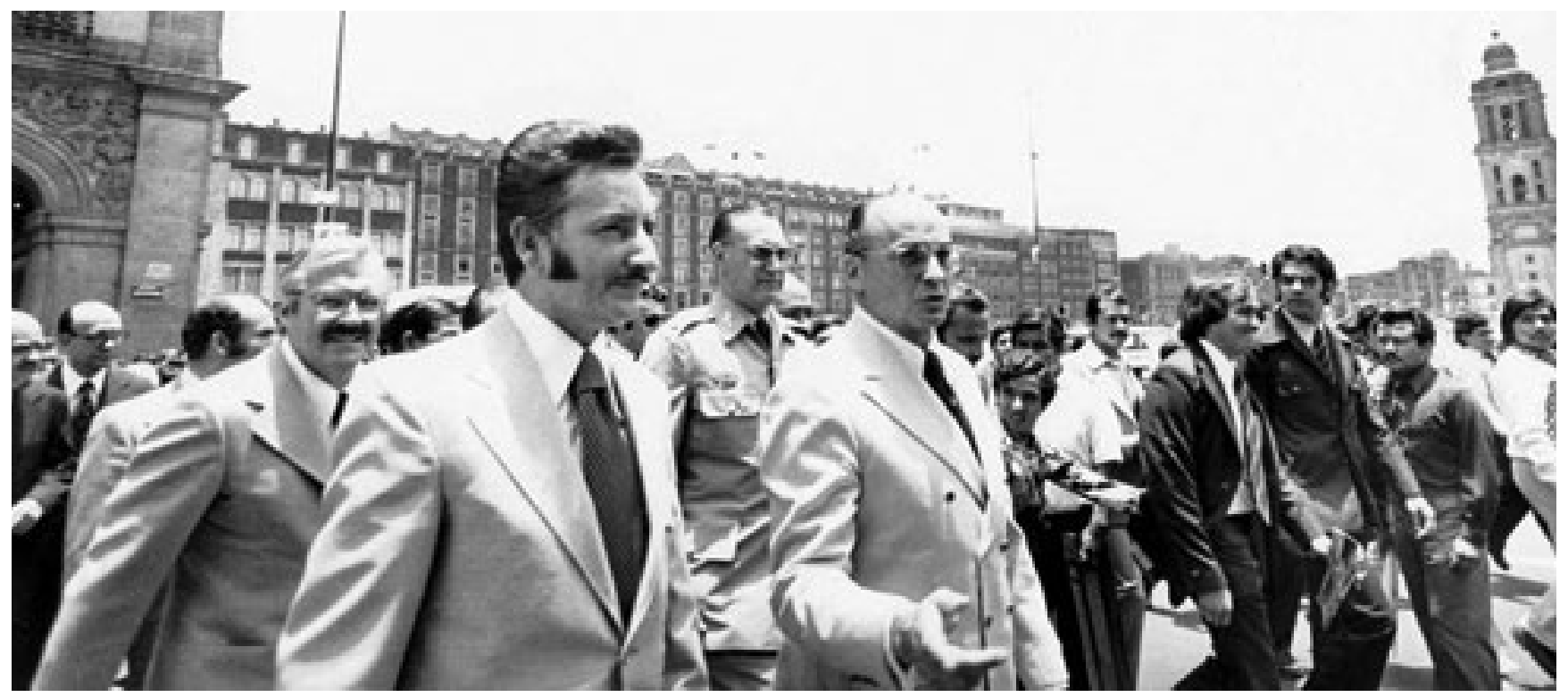

La Dirección Federal de Seguridad era la policía política del régimen. Uno de los directores fue Fernando Gutiérrez Barrios.

adheridas a dicha pirámide a nivel nacional, la cual todos los espacios políticos locales reproducían fielmente. En esta época la comisión de delitos comunes como robos, crímenes y otros actos de esta naturaleza eran extraños y se vivía en un tipo de sociedad controlada que aseguraba el dominio y el monopolio del poder y la violencia al Estado. México era así uno de los países más seguros en América Latina y en el mundo.

Sin embargo, las conductas "delictivas" de aquellos tiempos eran atribuidas principalmente a los disidentes de ese sistema. El Partido Comunista Mexicano había sido colocado como el enemigo principal desde el régimen de Miguel Alemán en i946. Así, sus miembros y partidarios fueron foco, durante este tiempo, de apresamientos, detenciones arbitrarias y encarcelamientos injustificados. Debemos recordar que la famosa Dirección Federal de Seguridad (DFS) de la Secretaría de Gobernación (Segob) fue creada en i947 y sus funciones, además de realizar espionaje político, consistían en sofocar a los grupos opositores al régimen, ubicar y detener a sus principales líderes. Para la década de los años setenta la DFs inició actividades contra el narcotráfico.

De igual manera, miembros de otras organizaciones opositoras fueron perseguidos y en muchos casos asesinados o desaparecidos, como en el caso del asesinato del líder Rubén Jaramillo en Morelos en i962, cometido por militares y policías locales. Por supuesto, no existía el concepto de derechos humanos y la legitimidad "revolucionaria" del partido de Estado era el elemento jurídico que se hacía valer frente a los enemigos del sistema. El delito de disolución social (artículo

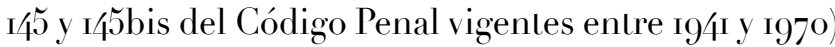
como arma legal, más el uso del Ejército y de cuerpos paramilitares sirvieron para mantener el dominio y estabilidad de este sistema. Las represiones del movimiento magisterial en I958 (Movimiento Revolucionario del Magisterio) y de los ferrocarrileros en ig 59 , fueron sólo un antecedente de la gran represión estudiantil de 1968 .

Por eso, y con justificada razón, Carlos Montemayor había señalado que en México la violencia de Estado había sido la característica fundamental de este régimen. ${ }^{2}$ El Ejército y todo el aparato policiaco, más que servir en lo general a la seguridad nacional y la ciudadanía, fueron aparatos al servicio de un régimen de partido único que buscaba perpetuarse por todas las vías posibles. Por estas razones históricas, lo que ha pasado en México después de los años ochenta tiene como antecedente histórico al Estado que generaba y administraba la violencia como parte de la propia lógica del poder autoritario.

Un régimen político basado en el control de las organizaciones sindicales y agrarias fue la base de la llamada estabilidad del régimen priista. Pero no sólo el Estado reprimía lo que en el exterior atentaba contra este dominio del partido hegemónico, como a los comunistas y disidentes abiertos, sino que dentro de las propias organizaciones sindicales y agrarias se impusieron dominios verticales de liderazgos amparados en su relación de subordinación del régimen. Además de que hay una historia de represiones, asesinatos y corrupciones generalizadas en el interior de estos sindicatos y organizaciones obreras y campesinas. 
Véase por ejemplo el libro de Francisco Cruz Jiménez, Los amos de la mafia sindical, ${ }^{3}$ en donde se narran las luchas por el poder dentro de los grandes sindicatos mexicanos, como el de los petroleros, el magisterio, los electricistas y otras organizaciones, que condujeron a crímenes y represiones, donde la corrupción y el manejo arbitrario de los fondos económicos fueron (y siguen siendo) la nota común. El Estado permitía este comportamiento, y en todos los casos apoyaba a los liderazgos que se sometían a la lógica del poder priista.

\section{Estado SIN DERECho}

Un Estado basado en normas legales ha sido una de las características para decidir si un régimen político ha pasado la prueba final para ser catalogado como democrático, es decir, si existen leyes claras, tribunales idóneos, jueces autónomos, absoluta imparcialidad en los procesos judiciales y, sobre todo, si los derechos de los ciudadanos frente al Estado son respetados minuciosamente. El carácter legal de un Estado es una base esencial en la que debe descansar su legitimidad. Siguiendo a O'Donnell, podemos afirmar que:

El Estado de derecho debería concebirse no sólo como una característica genérica del sistema legal y de la actuación de los tribunales, sino que considerarse la norma basada en la legalidad de un Estado democrático. Esto supone que existe un sistema legal que es, en esencia, democrático en tres sentidos. Uno, defiende las libertades políticas y las garantías de la democracia política. Dos, defiende los derechos civiles de todo el conjunto de la población. Y tres, establece redes de responsabilidad y accountability que comportan que todos los agentes, privados y públicos, incluyendo los cargos más altos del régimen, estén sujetos a controles apropiados y legalmente establecidos sobre la legalidad de sus actos. ${ }^{4}$

El derecho o la base legal de un régimen político en realidad son muchos derechos o ramas en las que se desperdiga esta funcionalidad, como el derecho penal, civil, etcétera. Lo que en México siempre ha estado cuestionado, y hoy en día sigue siendo una meta incumplida, es fundamentalmente el derecho público, es decir, todo el andamiaje institucional y regulatorio de la operación de todos los órganos del Estado en donde se suceden una serie de violaciones graves, constantes y repetidas a las normas legales que esos mismos órganos deberían de cumplir y no lo hacen; y cuando se cometen excesos, abusos y conductas criminales, la ley es inexistente para sancionar y castigar, o en el peor de los casos para simular que existe un Estado de derecho. No sólo para el caso de asuntos administrativos de corrupción pública - ahora un mal endémico en nuestro país -, sino, y más grave, cuando la actuación del poder público comete crímenes contra la población, como en diversos casos recientes de Tlatlaya, Ayotzinapa y muchos otros. En Tlatlaya, Estado de México, fueron ejecutadas 22 personas extrajudicialmente por militares el 3o de junio de 20I4. Posteriormente, el 26 de septiembre de ese año fueron desaparecidos 43 estudiantes normalistas de Ayotzinapa, en el estado de Guerrero. Así, el Estado se convierte en el principal gestor de la delincuencia y la espiral de violencia, tal como se ha vivido en México en las últimas décadas. Analizando el tema de enorme profundidad, las violencias sistémicas, Aaron Beck ha señalado que en países asolados por grandes violencias, uno debe remitirse indefectiblemente a las élites dirigentes, que en la mayoría de los casos son las culpables de generar estos episodios de violencias masivas. ${ }^{5}$

El Estado debe ser una parte de todo el sistema legal y someterse él mismo a las regulaciones y sanciones previstas en las normas jurídicas. En la teoría política el origen de la separación de poderes tenía como una de sus razones fundamentales la premisa de que ningún poder público, el Congreso o el Ejecutivo, pudiera tener todo el poder. La idea de contrapeso entre poderes era una regla fundamental como ancla de la democracia. El Poder Judicial venía entonces a constituir el poder de procesar y castigar no sólo en el espacio del derecho civil sino en el de los poderes públicos. Así, la misma idea de democracia era consustancial a la idea de legalidad como una misma cosa. ¡Por qué en México no ha sido posible la instauración de un verdadero Estado de derecho? La respuesta principal a esta interrogante reside en el hecho de que las élites dominantes en este país siguen actuando dentro del marco weberiano del patrimonialismo, es decir, como una extensión de su poder sin sujeción a las reglas de la democracia y el derecho.

El manual de la impunidad, por supuesto, incluye la idea de que se hace todo para cumplir la ley. Se crean fiscalías especiales para investigar sucesos trágicos o asesinatos, y el gobierno declara en todos los casos "que no le temblará la mano para castigar a 
los culpables, sean quienes sean". Se crean nuevas instituciones ad hoc o las que están en funcionamiento se ponen en acción y se crea un ambiente inicial de que se cumplirá la ley. Todo es una gran simulación y se deja pasar el tiempo para que el olvido sea la respuesta final. Para la élite dominante, la ley en México es el crimen perfecto.

\section{Ejército cono SuJETo dentro} DE LA VIOLENCIA INSTRUMENTAL

El régimen de partido único fue una herencia de la Revolución mexicana de igı a I9г7, como resultado de un arreglo surgido en I929, luego del asesinato del presidente electo Álvaro Obregón en I928, cuando las facciones revolucionarias residuales, bajo el mando del así llamado jefe máximo, el general Plutarco Elías Calles, decidieron crear el PNR y acabar con las luchas de caudillos para dar paso a una era en la que prevalecieran las instituciones políticas. El arreglo fundamental detrás de la creación del PNR era el de terminar el problema central de la posrevolución, que consistía en que las luchas y principales divisiones se llevaban a cabo con motivo de la sucesión presidencial. Como se sabe, en México desde ese año hasta posiblemente la elección de 1988 , la designación del candidato presidencial era una decisión del presidente saliente.

Sin embargo, hasta la última rebelión del general Saturnino Cedillo en I938 (la rebelión de I938 fue después de la expropiación cardenista del petróleo y fue impulsada por las empresas petroleras extranjeras, dolidas por este hecho y como un intento para revertirla. Véase al respecto Jorge Alberto Lozoya, El Ejército mexicano) ${ }^{6}$ pero principalmente en las rebeliones de r923 y r929, con motivo de la sucesión presidencial, el Ejército mexicano se había dividido y diversas facciones a su interior lo habían utilizado para intentar tomar el poder por las armas. Todas estas rebeliones fracasaron y el núcleo de una nueva clase dirigente quedó al mando del poder político que se extendió por muchas décadas siguientes. Lo importante fue que el Ejército se estableció como la garantía central de la estabilidad política frente a los enemigos de la Revolución mexicana. Existe un hilo explicativo de la presencia y actividades del Ejército mexicano en lo que se puede llamar la violencia instrumental del Estado mexicano contra todo lo que fuera considerado extraño a la funcionalidad de este sistema de partido único. Pensamos que el Ejército ha transitado en-

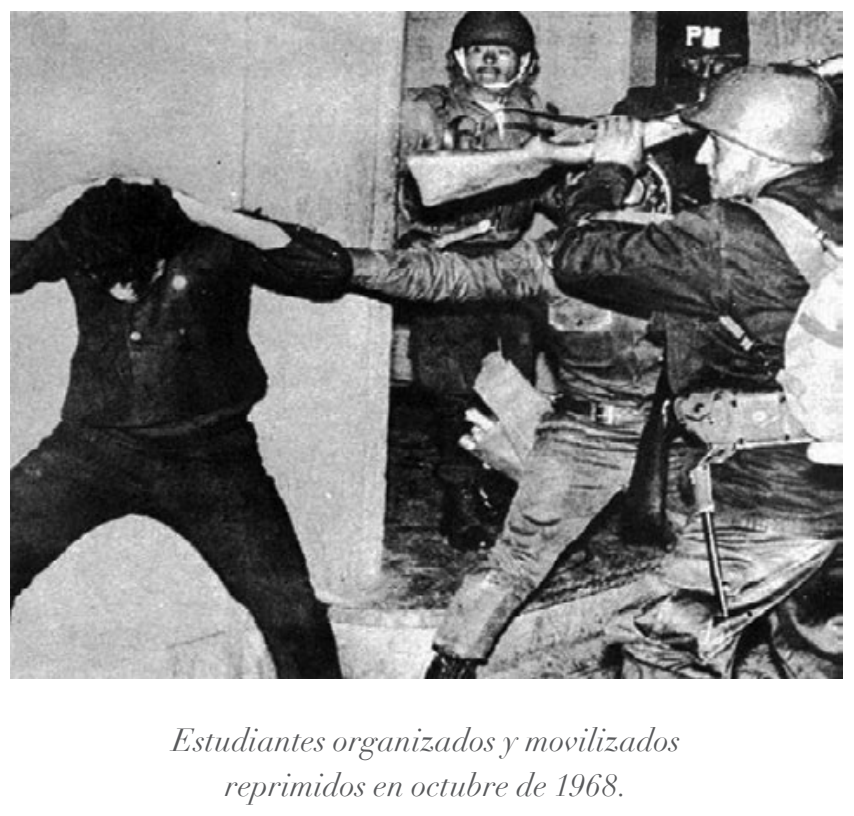

tonces como sujeto de la violencia instrumental contra comunistas, movimientos sindicales, estudiantiles y guerrilleros de la vieja etapa a la de seguir garantizando la estabilidad de este sistema, aun con la llamada alternancia política desde 2000, y su uso extendido en la guerra contra los cárteles de la droga mexicanos. El problema principal en el pasado y en el presente es que el Ejército actuaba y actúa en un marco de absoluta impunidad, con violaciones graves contra comunidades y personas. Tenía y sigue teniendo el permiso para aniquilar al enemigo sin condicionamientos de ninguna especie. No es responsable ante ningún cuerpo legal y se supone que sólo obedece órdenes del presidente de la República.

Hasta 2013, la Comisión Nacional de Derechos Humanos (CNDH) había recibido 8, I5̆ quejas de abusos del Ejército y ri6 de casos de serias violaciones a los derechos humanos. También investigaba la desaparición de 2,143 personas en las que se encontraba evidencia del involucramiento de agentes del gobierno.

Aaron Beck clasifica a las violencias de acuerdo con sus naturalezas, y la violencia instrumental es aquella que se impone para consolidar regímenes políticos. La violencia es de este modo instrumental, pues es un trabajo que hay que realizar por motivos políticos o ideológicos. Esta violencia es particularmente peligrosa porque suele estar basada en la doctrina de "el fin justifica los medios". Las burocracias policiacas y castrenses son los funcionarios que ejecutan estas políticas en un marco de amplia libertad y, por tanto, de gran impunidad. En México prácticamente nadie ha sido juzgado y encarcelado a raíz de las masacres cometidas en el pasado, como en el 2 de octubre de 


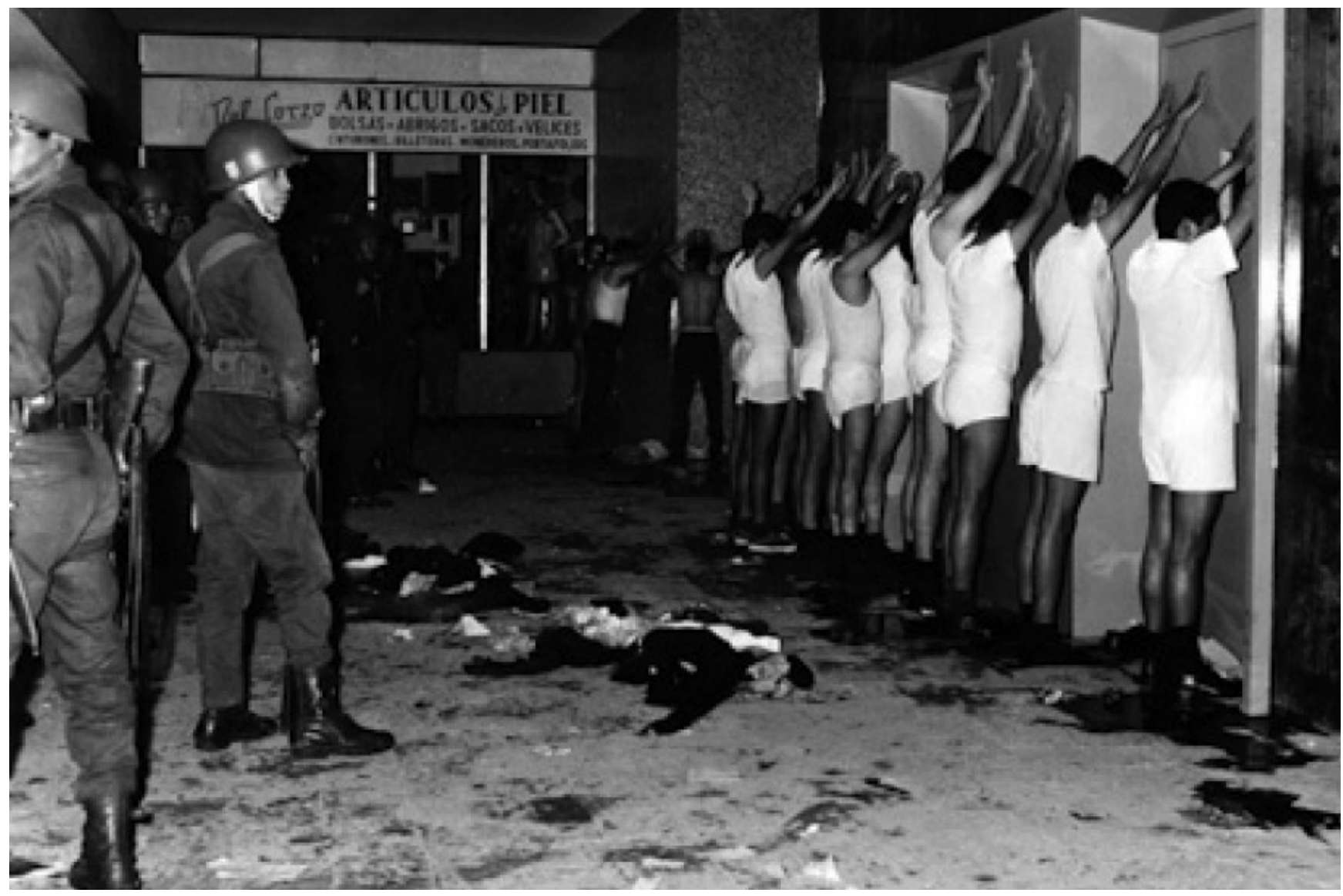

Las manifestaciones estudiantiles fueron disueltas con la detención de lideres y la masacre de manifestantes en 1968.

I968, el jueves de corpus en I97ı, Aguas Blancas en el estado de Guerrero en i995, Acteal en Chiapas en r997 y así hasta 20ı́, año en que desaparecieron 43 estudiantes de la escuela normal de Ayotzinapa, también en el estado de Guerrero, que ha conmocionado a la sociedad mexicana, después de décadas de abusos y atropellos cometidos por las llamadas "fuerzas del orden".

El Ejército se usaba discrecionalmente cuando ya no había una opción política, como en el caso de las represiones magisteriales y de los ferrocarrileros en I958 y 1959, pero aumentó su participación con los movimientos estudiantiles y las primeras guerrillas en la década de los años sesenta. El Instituto Politécnico Nacional (IPN) fue ocupado militarmente en rg556, así como la UNAM en ig68, previo a la masacre estudiantil de ese año.` Igualmente, el uso de bandas paramilitares fue una estrategia para esconder esta participación directa y como nueva táctica en la lucha contra los enemigos del régimen. El batallón Olimpia que participó en los hechos de i968, los halcones en la represión de i97ı, los zetas que se iniciaron como un cuerpo de élite militar para abatir a los zapatistas en Chiapas y que luego fueron cooptados por el cártel del Golfo, representan casos conspicuos de los cuerpos paramilitares gestados directamente por el gobierno mexicano en el pasado.

\section{Neoliberalismo, desestructuración}

SOCIAL Y VIOLENCIA

Las políticas neoliberales, tales como la "flexibilización laboral", las reducciones a los subsidios y el gasto social, las privatizaciones de la mayoría de las empresas estatales - herencia del modelo económico anterior - , la liberalización financiera y el desmembramiento de las tierras comunales, que se han aplicado en México consistentemente desde i982 hasta la fecha, han provocado la destrucción del tejido social del país y han generado las condiciones perfectas para la consolidación de las actividades criminales, promovidas principalmente por los cárteles de la droga que ya existían en forma embrionaria desde décadas anteriores y que en conjunción con gobiernos y policías corruptos explican el cocktail de violencia creciente que ha vivido el país en los últimos años.

Simplemente la llamada "guerra contra las drogas" iniciada por el presidente Felipe Calderón ha 


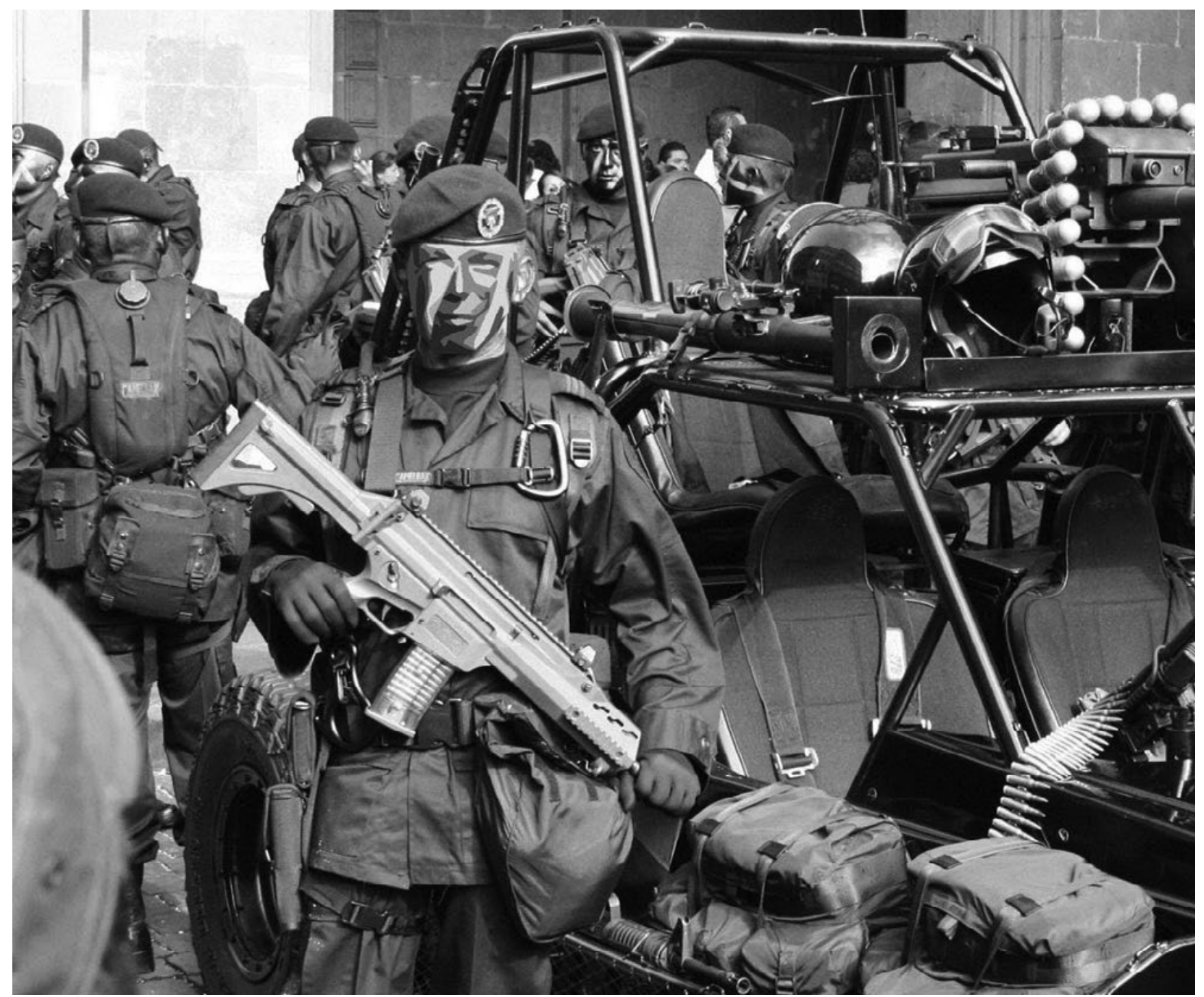

Además de incursionar en la "guerra contra las drogas", el Ejército mexicano asume un papel preponderante en el resguardo del modelo neoliberal

resultado en la muerte de más de 6o,ooo personas y 26,00o desaparecidos, entre 2006 y 2012. El presidente Felipe Calderón llegó a la Presidencia luego de un fraude electoral en julio de 2006 y la estrategia de la "guerra contra las drogas" fue concebida como un instrumento de legitimación con enormes costos para todo el país. El ciclo de fraudes electorales en el país, como el de ig88 y el de 2006 (en el pasado de hegemonía priista se dieron otros en 1940 y 1952$)$ debe verse como parte indisoluble del rompimiento del Estado legal y los generadores de la violencia e impunidad en el país. Esta estrategia, continuada por el nuevo presidente Enrique Peña Nieto, ha conducido al país hacia un túnel de violencia que no sólo ha arrastrado a los cárteles de la droga a una confrontación entre ellos por la defensa de territorios y mercados, sino a la muerte de civiles inocentes, periodistas y defensores de derechos humanos. Io3 periodistas han sido asesinados en México entre 2000 y $2015^{8}$ como resultado del asesinato del periodista Rubén Espinosa en la Ciudad de México el 3ı de julio. En $20 ı 5$ la racha de crímenes continúa en el país, ya que fueron asesinadas cerca de 18,000 personas. Es decir, la lucha contra los cárteles de la droga ha sido un gigantesco teatro para diseminar la violencia y el miedo en todo el país, como una estrategia de control y dominio del Estado sobre la población.

¿Por qué el neoliberalismo HA INCREMENTADO LA VIOLENCIA EN MÉXICO?

Como hemos ya insinuado, hay varias razones que explican cómo la aplicación de estas políticas afectó la 
cohesión económica y social del país y preparó el terreno para que la violencia en el país se acrecentara de manera exponencial:

I. El campo mexicano ha vivido una especie de desastre económico y social. Las primeras políticas neoliberales quitaron subsidios y asistencia, luego se instrumentaron cambios constitucionales para liberar a las tierras comunales dentro de un mercado en el que los campesinos tradicionales fueron los perdedores. El Tratado de Libre Comercio de América del Norte (TLCAN) ha hecho que no puedan competir los cultivos tradicionales con los productos agrícolas subsidiados provenientes de Estados Unidos. Todo lo anterior provocó una salida masiva de migrantes a Estados Unidos, y así parte del territorio mexicano quedó desolado y desamparado facilitando el ingreso de bandas criminales. Por último, y no menos importante, ha sido el surgimiento del cultivo de drogas en estados como Guerrero, Michoacán, Sinaloa y otros, como paliativo y respuesta a la crisis campesina. Hay que subrayar el hecho de que el comercio de drogas México-Estados Unidos está calculado en cerca de 30 mil millones de dólares anuales.

2. Ciudades como Reynosa, Tijuana y Ciudad Juárez, situadas en la frontera con Estados Unidos, con grados de violencia rampante, se han distinguido por ser territorios de empresas maquiladoras que han sido incapaces de promover procesos de industrialización endógenos y han continuado siendo una suerte de espacios geográficos residuales fronterizos. Ante la ausencia de una industrialización que provocara la mejora sustancial de las economías locales y los lazos sociales, la violencia se ha convertido en un elemento estructural. Debemos recordar que 9 o por ciento de las drogas pasan por varias de estas ciudades y eso explica su importancia estratégica para el crimen organizado y los gobiernos locales en todas sus jerarquías que participan en dichas actividades.

3. Con un crecimiento bajo de la economía en todos estos años de neoliberalismo, con crisis financieras en ig 82 y i994, que han afectado principalmente a las clases medias y bajas del país, el dinero del comercio de las drogas y de las actividades asociadas como secuestros y ex- torsiones, ha venido a ser una especie de nuevo mercado para la obtención de recursos.

4. Sostengo la hipótesis de que con la privatización de centenares de empresas públicas en la década de I98o, que eran fuente directa de ingresos de toda una gama extensa de funcionarios gubernamentales y empresas mexicanas proveedoras, los cárteles de la droga que ya existían bajo el cobijo, vigilancia y, en algunos casos, como creación directa de funcionarios públicos, se convirtieron en una especie de nuevas empresas paraestatales, es decir, en negocios amparados por el propio gobierno. Toda la literatura escrita sobre los cárteles de la droga en México ha señalado reiteradamente la conjunción de funcionarios y agentes gubernamentales, así como militares con los cárteles de la droga. Asimismo, la revista Proceso ha indicado consistentemente este hecho. Por ello, la "guerra contra las drogas" resultó tan contradictoria y falaz. Entre otros libros, pueden consultarse: Anabel Hernández, Los señores del narco; Ricardo Ravelo, El narco en México. Historia e historias de una guerra. ${ }^{9}$ La decisión del gobierno de Estados Unidos de cerrar el tráfico de drogas directo de Colombia a Estados Unidos, a mediados de la década de los noventa, concomitante con el TLCAN, hizo que dicho comercio se trasladara a territorio mexicano. Con esta decisión los cárteles mexicanos recibían un regalo al ser los principales promotores del comercio de drogas a Estados Unidos. La pregunta que hay que hacerse entonces es sobre el verdadero objetivo que perseguía el gobierno de Estados Unidos con esta decisión.

5. La in-transición política a la democracia ha sido otro factor central en la creciente ola de criminalidad en el país. El Estado autoritario, basado en la hegemonía priista se ha ido, pero en su lugar vagan sus fantasmas. Se pensaba que el tránsito a las instituciones democráticas era un proceso automático, y lo que hemos vivido en estos años es una simulación. Existen en la ley instituciones y procedimientos democráticos, pero en la realidad hay un enorme vacío de legitimidad que es una fórmula para alimentar el crimen y la constante violación a las normas legales. La historia de fraudes electorales y corrupción política a todos los niveles exhibe en México el grado de descomposición de sus clases dirigentes. México es un 
país en donde el propio presidente es acusado de corrupción sin que pase nada y eso dice mucho del nivel de democracia y Estado legal en el que se vive. La periodista Carmen Aristegui hizo pública la posesión de una casa del presidente Peña Nieto con un valor de 7 millones de dólares obtenida por medio del grupo Higa, que ha estado ligado con el presidente desde que éste era gobernador del Estado de México. El único resultado fue que la periodista Aristegui fue despedida de su programa de radio en otro caso lamentable de censura.

Como podemos ver, luego de exponer toda una serie de razonamientos sobre el contexto de la violencia y la impunidad en México, éstos no son sólo producto de la malignidad de grupos criminales y de autoridades pusilánimes, son el resultado de una serie de procesos políticos que se han ido imbricando a lo largo de todos estos años. Sólo la reconstrucción del tejido social, el arribo de una coalición de fuerzas políticas representativas de los reclamos de la sociedad civil y la promoción de un nuevo camino del desarrollo económico atendiendo las necesidades más apremiantes de las clases bajas, es como pensamos que México podrá salir de esta vorágine de violencia e impunidad.

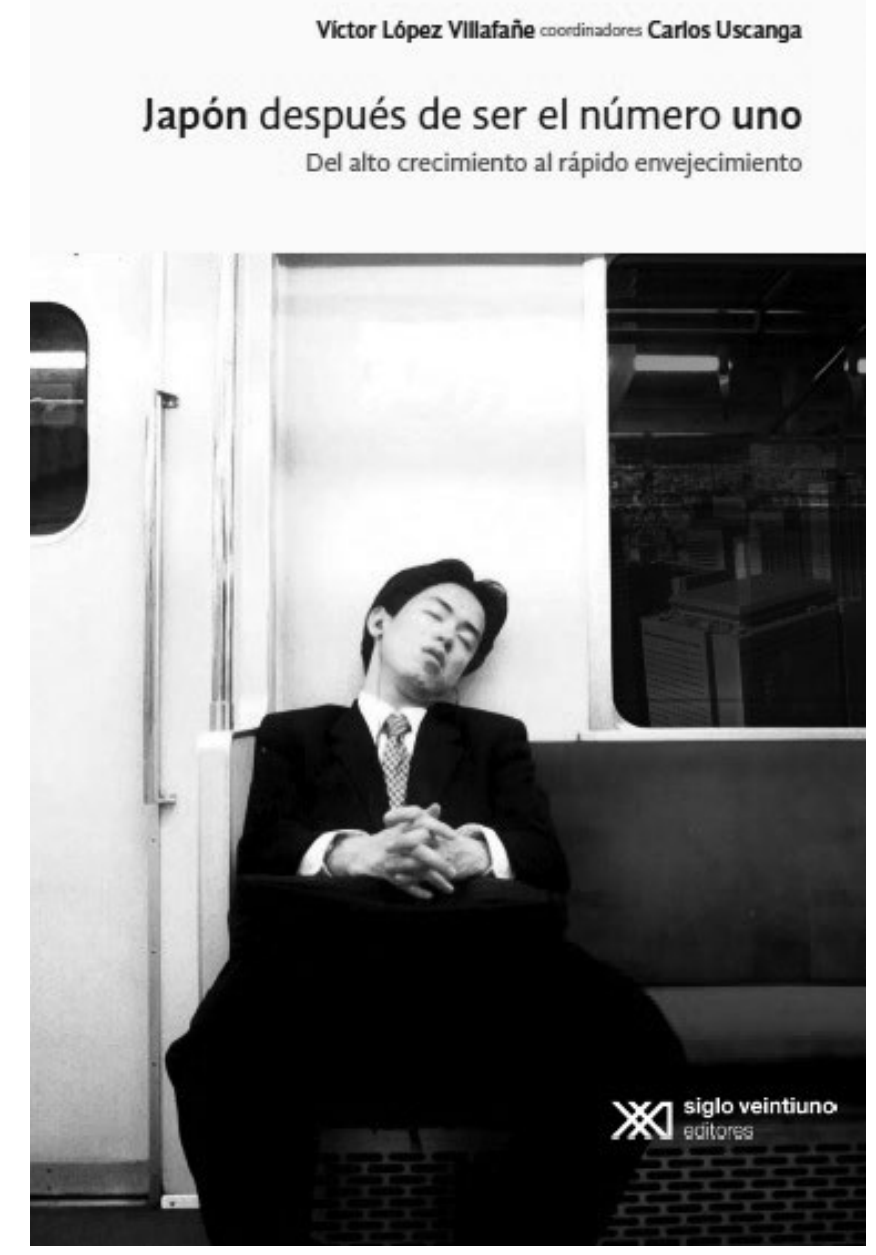

\section{$-\operatorname{notas} \cdot-$}

'Víctor Ballinas (22 de julio de 20ı5), "México ocupa el sitio 58 de 59 índices de impunidad global, indica estudio en el Senado", La Jornada, p. I9.

${ }^{2}$ Carlos Montemayor (20Io), La violencia de Estado en México. Antes y después de 1968, México, Debate.

${ }^{3}$ Francisco Cruz Jiménez (2013), Los amos de la mafia sindical, México, Temas de Hoy.

${ }^{4}$ Guillermo O'Donnell, "La irrenunciabilidad del Estado de derecho", ponencia presentada en el Seminario Internacional "La Reinvención de la Política y la Ciudadanía" (en línea),
Barcelona, España, 22 y 23 de enero de 200I. Disponible en www.enj.org (fecha de consulta).

${ }^{5}$ Aaron Beck (2003), Prisioneros del odio. Las bases de la ira, la hostilidad y la violencia, Paidós, pp. 23 y 2/4.

${ }^{6}$ Jorge Alberto Lozoya, El Ejército mexicano, El Colegio de México, Jornadas 65, pp. 64-65.

7 Jorge Alberto Lozoya, op. cit., p. I25.

${ }^{8}$ La Jornada, 2 de agosto de 2015

9 Anabel Hernández (2010), Los señores del narco, México, Grijalbo; Ricardo Ravelo (2011), El narco en México. Historia e historias de una guerra, México, Grijalbo. 